\title{
THE ROLE OF AMORPHOUS PHASE CONTENT ON THE ELECTRICAL PROPERTIES OF ATMOSPHERIC PLASMA SPRAYED (Ba,Sr)TiO $\mathrm{COATINGS}$
}

\author{
Jiri Kotlan, a,, ${ }^{\mathrm{a}}$, Ramachandran Chidambaram Seshadri ${ }^{\mathrm{c}}$, Sanjay Sampath ${ }^{\mathrm{c}}$, Pavel Ctibor $^{\mathrm{a}}$ \\ a - Materials Engineering Department, Institute of Plasma Physics CAS, v.v.i., Za Slovankou 3, Prague 8, \\ Czech Republic \\ b - Department of Electrotechnology, Faculty of Electrical Engineering, Czech Technical University in \\ Prague, Technicka 2, Prague 6, Czech Republic \\ c - Center for Thermal Spray Research, Department of Materials Science \& Engineering, Stony Brook \\ University, Stony Brook, NY 11794-2275, USA \\ * corresponding author: kotlan@ipp.cas.cz, tel.: +420266053717
}

\begin{abstract}
$(\mathrm{Ba}, \mathrm{Sr}) \mathrm{TiO}_{3}$ coatings deposited on carbon steel substrates were successfully prepared by an atmospheric plasma spray system. Three sets of samples containing different amount of both crystalline and amorphous phases were deposited and consequently studied in order to determine their electrical properties. The results show a clear correlation existing between the amorphous phase content and coating's electrical properties. The resistivity increases with increase of amorphous phase content. Relative permittivity for low frequencies decreases and become more stable with frequency tuning when amorphous phase content increased. The maximum relative permittivity value is in the range $75-200$ for frequency $1 \mathrm{kHz}$. The loss factor varies between 0.23 and 0.03 for all studied samples. The loss factor is at the lower limit of these values and frequency much less dependent when the coating contains $15 \mathrm{wt} . \%$ of amorphous phase and more. The band gap of all samples is between $2.75 \mathrm{eV}$ and $2.90 \mathrm{eV}$. Microstructure and hardness were evaluated in order to determine basic mechanical properties of deposits.
\end{abstract}

Keywords: Atmospheric Plasma Spray; B. X-ray methods; C. Electrical properties; D. Perovskites 


\section{INTRODUCTION}

Ferroelectric and paraelectric ceramics play an important role in electronic applications, since these materials have high relative permittivity values. High permittivity value allows the material to act as gates in dielectric devices. The $\mathrm{BaTiO}_{3}$ which belong the aforementioned category of materials is extensively studied and applied in a wide variety of applications such as multilayer ceramic thermistors, piezoelectric transducers, capacitors and actuators [1]. This group of materials is principally produced by powder sintering or high temperature co-firing (HTCC) methods. Disadvantage of conventional powder sintering technologies lies in the fact that they cannot be easily used in coatings or direct writing technology. Atmospheric Plasma Spray (APS) technology can be effectively used to deposit ceramic layers on different substrate materials and over large areas at moderate to low deposition temperatures [2]. Barium titanate and its doped variants were and still are extensively used for its excellent ferroelectric, piezoelectric and thermoelectric properties in electronic industry $[3,4]$. Sintered $\left(\mathrm{Ba}_{0.4} \mathrm{Sr}_{0.6}\right) \mathrm{TiO}_{3}$ ceramics was studied in order to determine the effect of grain boundary on the energy storage properties and dielectric breakdown strength [5]. There are a few articles available in the open literature, which deals with the study on the dielectric properties of plasma and HVOF deposited barium strontium titanate (BST) coatings $[6,7,8]$. A significant influence of the amorphous phase content on the dielectric constant values was observed on $\mathrm{BaTiO}_{3}$ coatings that were prepared by various spray deposition techniques. $\mathrm{BaTiO}_{3}$ coatings sprayed by the supersonic plasma spray system (HEPJet) showed that that defects like porosity and voids can reduce the piezoelectric effect in the resultant coatings [9]. Among the spray parameters, the spray distance was found to significantly affect the photocatalytic activity of plasma sprayed $\mathrm{BaTiO}_{3}$ coatings [10]. The importance of substrate temperature during plasma spray deposition of coatings was demonstrated in a study, which showed that with the increase in substrate temperature the inter-splat bonding increases and this consequently results in the increase in the relative permittivity values [11]. Solidification of molten particles during plasma spraying is accompanied by extremely high cooling rates [12]. Rapid cooling promotes the formation of amorphous phases in the coating and thus various material 
properties are affected by the degree of crystallinity. Thermal annealing is important post-deposition process which can be effectively used to tailor the dielectric properties of atmospheric plasma sprayed dielectric ceramic deposits [13]. In our previous publication which focused on electrical breakdown strengths of selected atmospheric plasma sprayed ceramics, it was found that the electrical breakdown strength increased with increasing levels of amorphous content in $(\mathrm{Ba}, \mathrm{Sr}) \mathrm{TiO}_{3}$ coatings [14]. The current investigation is focused on studying the role of amorphous phase content on mechanical and some electrical properties of about $0.5 \mathrm{~mm}$ thick coatings. We report namely the $\mathrm{DC}$ resistivity, relative permittivity and loss factor of plasma deposited ( $\mathrm{Ba}, \mathrm{Sr}) \mathrm{TiO}_{3}$ coatings prepared under different spray conditions. The influence of spray distance is a key parameter in this study. The relative permittivity and loss factor were studied in the frequency range from $50 \mathrm{~Hz}$ to $1 \mathrm{MHz}$.

\section{EXPERINMENTAL DETAILS}

\subsection{COATING PREPARATION}

Three sets of samples sprayed at different spray distances namely $100 \mathrm{~mm}, 150 \mathrm{~mm}$ and $200 \mathrm{~mm}$ were prepared and the corresponding coatings were labeled as BST 100, BST 150 and BST 200. The Accuraspray-g3 sensor (TECNAR Automation Ltd., St-Bruno, Qc, Canada) was used to measure the surface temperatures and velocities of the sprayed particles. Coatings were deposited on grit blasted substrates having dimensions $25 \times 230 \times 3.2 \mathrm{~mm}^{3}$ made out of low carbon steel. Coatings thicknesses were $0.36 \mathrm{~mm}, 0.48 \mathrm{~mm}$ and $0.41 \mathrm{~mm}$ for BST 100, BST 150 and BST 200 respectively. The spray parameters and powder details are listed out in Table 1.

\subsection{CHARACTERIZATION OF COATINGS}

All the coatings and the feedstock powder were analyzed by X-ray diffraction. The XRD was done using the D8 Discover Bruker diffractometer operated in the Bragg-Brentano mode with filtered $\mathrm{CuK \alpha}$ radiation and 1D LynxEye detector. Diffraction patterns were analyzed within the frame of the Rietveld method available in TOPAS 4.2 software. Samples were cut and ground to the dimensions of approximately $25 \mathrm{x}$ $20 \times 2.8 \mathrm{~mm}^{3}$. A three electrode measuring system was employed for all electrical properties measurements. Carbon steel substrate of thickness $2.3 \mathrm{~mm}$ was used as one of the electrodes. Two other 
aluminum electrodes were sputtered on the coating surface under reduced pressure. Capacity measurements were carried-out in a frequency range from $50 \mathrm{~Hz}$ to $1 \mathrm{MHz}$. For low frequency measurements $(50 \mathrm{~Hz}-100 \mathrm{kHz})$ a Hioki $3522-50$ LCR HiTester was used. The device was set to four times the average of all values. The Agilent 4285 instrument equipped with Agilent 16451B sample fixture module was employed to measure frequency range measurements between $75 \mathrm{kHz}$ to $1 \mathrm{MHz}$. The frequency step was progressively increased and applied AC voltage of $1 \mathrm{~V}$ kept constant in both devices. The electric field was applied along the spray direction (i.e., perpendicular to the substrate surface). The relative permittivity $\varepsilon_{r}$ was calculated from measured capacities and specimen dimensions using equation $\varepsilon_{r}=(C \cdot d) /\left(A \cdot \varepsilon_{0}\right)$ where $C(\mathrm{~F})$ is electrical capacity of the sample, $d(\mathrm{~m})$ is samples thickness, $A\left(\mathrm{~m}^{2}\right)$ is area of measuring electrode and $\varepsilon_{0}$ is permittivity of vacuum $(8.854 \mathrm{e}-12 \mathrm{~F} / \mathrm{m})$. The same LCR-meters were, at the same moment, used for the loss factor measurement. Loss factor (tg $\delta$ ) was measured for the same frequencies as capacity. The volume resistivity was measured on the same samples for capacity measurements using Keithley 6517B high resistance meter. Applied voltage for all resistance measurements was set to $100 \pm 0.16 \mathrm{~V}$. Customized Keithely 6104 shielded test enclosure was used in order to avoid error from ambient noise. Resistivity was calculated from measured resistance and specimen dimensions using equation $\rho=(R \cdot A) / d$ where $R(\Omega)$ is electrical resistance of the sample, $A\left(\mathrm{~m}^{2}\right)$ is area of measuring electrode and $d(\mathrm{~m})$ is samples thickness. All electrical properties measurements shows electrical response of the whole coating-substrate system because the substrate served as one of the electrodes (earlier described in [14]). Diffuse reflectance was measured by UV-VIS-NIR scanning spectrophotometer (Shimadzu, Japan) with a multi-purpose large sample compartment and corresponding band-gap energy was estimated. The reflectance curves obtained between 200 and $2000 \mathrm{~nm}$ were converted to absorbance and recalculated [15] to band-gap energy, $\mathrm{E}_{\mathrm{bg}}$. Metallographic samples were prepared using Tegramin-25 automatic polishing system (Struers, Denmark) to ensure identical preparation conditions for all samples. Cross sections were observed using EVO MA 15 scanning electron microscope (Carl Zeiss SMT, Germany) equipped with EDX detector. The porosity was measured on the 
polished cross-sections of the deposits using light optical microscopy. Ten images of each sample were taken from randomly selected areas at $400 \times$ magnification. The volume percentage of porosity was estimated using image analysis software Lucia G (Laboratory Imaging, Prague, Czech Republic). Only the pores which are larger than $3 \mu \mathrm{m}$ in diameter were taken into account for the porosity measurements. The microhardness measurement was made using SVK-C2 Vickers microhardness tester, (Mitutoyo, Japan). A load of $300 \mathrm{~g}$ and a dwell time of $15 \mathrm{~s}$ were used to evaluate the hardness. Hardness values were measured at 10 random locations on the polished cross-section of a coating and average values were considered in order to compare the coatings. The indentation tests were performed at room temperature on the same polished cross-sections as were used for the SEM and optical microscopy.

\section{RESULTS AND DISCUSSION}

\subsection{INFLIGHT DIAGNOSTICS OF SPRAYED PARTICLES}

The average velocities and surface temperatures of the particles obtained from the Accuraspray-g3 sensor are summarized in Table 2. The working of Accuraspray-g3 ensemble particle stream sensor data can be referred elsewhere [16]. The melting point BST is $2080{ }^{\circ} \mathrm{C}$. It could be inferred from the ensemble sensor diagnosis data that, the particle temperature and velocity decreases with increasing of spray distance. The velocities of particles measured at $200 \mathrm{~mm}$ spray distances is significantly lower than the velocities measured at $100 \mathrm{~mm}$ and $150 \mathrm{~mm}$ spray distances. Particles temperature seems to decrease to at least $100{ }^{\circ} \mathrm{C}$ with every $50 \mathrm{~mm}$ increment in the spray distance.

\subsection{PHASE ANALYSIS OF THE THERMAL SPRAY DEPOSITS}

The XRD patterns of the surfaces of the coatings deposited under different spray distances are compared with the feedstock powder, Fig. 1. In the figure, vertical shift was introduced in order to make the comparison more illustrative. The identified phases are denoted by special symbols above the corresponding reflections.

Rietveld refinement was performed with the aim to (a) verify the presence of the identified phases, (b) refine lattice parameters of the identified crystalline phases, (c) calculate average sizes of crystallites or, 
more precisely, coherently scattering domains (CDD) and (d) estimate amorphous content in coatings. Results are presented in Table 3.

The BST feed stock has both $\mathrm{BST}$ and $\mathrm{BaTiO}_{3}$ as major phases, whereas the coatings show the presence of BST and an amorphous content, which could be inferred from Fig. 1. The stoichiometry of barium and strontium atoms occupying the $(0,0,0)$ site in primitive cubic lattice, as refined by Rietveld method, was similar in the deposits sprayed under 100 and $150 \mathrm{~mm}$ spray distances, i.e. $\mathrm{Ba}_{0.35} \mathrm{Sr}_{0.65}$, which is less balanced compared to $\mathrm{Ba}_{0.45} \mathrm{Sr}_{0.55}$ for $200 \mathrm{~mm}$. In case of the BST feedstock the refined occupancies show $\mathrm{Ba}_{0.60} \mathrm{Sr}_{0.40}$ stoichiometry which is slightly different from the information provided by feedstock supplier, i.e. $\mathrm{Ba}_{0.68} \mathrm{Sr}_{0.32} \mathrm{TiO}_{3}$.

\subsection{ELECTRICAL PROPERTIES OF THE DEPOSITS}

The DC resistance was measured until the resistance value was fully stabilized. Measuring time step size was set to one data point per second (dps) and the data were continuously recorded and processed until stabilization was established. It took between 60 and 90 minutes for the DC resistance to stabilize. This behavior is associated with the dielectric polarization, i.e. capacitance charging. When all transient processes are done, the resistance value represents the real DC resistance. For illustration, the time evolution of DC resistance for one of the BST 150 samples is given, Fig. 2.

Obtained results show that samples sprayed at $150 \mathrm{~mm}$ have the highest DC resistivity and samples sprayed at $100 \mathrm{~mm}$ have in four orders of magnitude lower value, Fig. 3. Standard deviation for all samples sprayed at different spray distances is lower than $10 \%$. A clear correlation between amorphous phase content in coatings and DC resistivity was observed. Samples with high amorphous phase content exhibit high resistivity.

Frequency dependence of relative permittivity decreases with increasing of amorphous content in the coating, Fig. 4. Sample BST 150 with estimated amorphous content of about 38 wt.\% has weak frequency dependence and significantly lower permittivity value especially in low frequency range when compared 
to other samples. Standard deviation is lower than 3 for all measured frequencies. Two other samples exhibit higher permittivity value as well as bigger standard deviation. BST 100 has similar frequency dependence as BST 200. That holds true for low frequencies. For high frequency range is the behavior rather like for BST 150.

Frequency dependence of loss factor, that represents power losses in dielectrics, is given, Fig. 5. BST 100 sample exhibits significantly higher loss factor when compared with two other samples. High loss factor as well as low DC resistivity is commonly associated with presence of oxygen vacancies in the coatings [17]. Stoichiometry is affected in a reducing plasma atmosphere of APS process. The re-oxidation of particles can take place with increase of spray distance $[\mathbf{1 8}, \mathbf{1 9}]$. This is also illustrated by DC resistivity measurements Fig. 3. BST 100 has significantly lower resistivity as well as the highest loss factor among all the samples. Nevertheless, dielectric properties are most likely affected by degree of crystallinity in the coating. This two effects takes place in the case of BST coating. Frequency stable permittivity as well as loss factor values are advantageous for applications where the signal frequency is tuned.

\subsection{OPTICAL PROPERTIES OF THE COATINGS}

To assess the shape and the position of the absorption edge of the material we measured the total reflectance $R_{\text {total }}$ by integration sphere. Following assumption that the transmittance is zero, the absorptance is then calculated as $1-R_{\text {total }}$. The relation between absorption coefficient $\alpha$ and $1-R_{\text {total }}$ is however not as straightforward. Data obtained from reflectance measurements was used for estimation of the band gap. The band-gap estimation is given, Fig. 6 .

The band gap lies between $2.75 \mathrm{eV}$ and $2.9 \mathrm{eV}$ for all spray distances when assuming direct transition between valence and conduction band [20]. Band gap values for plasma sprayed $\mathrm{BaTiO}_{3}$ were reported between $2.64 \mathrm{eV}$ and $3.25 \mathrm{eV}$ [10]. Similar value $3.2 \mathrm{eV}$ was determined for $\mathrm{SrTiO}_{3}$ single crystal [21]. 
Different run of the curve corresponding to BST 100 spectra represents lower absorbance for radiation energies below $3 \mathrm{eV}$.

\subsection{MICROSTRUCTURAL OBSERVATIONS OF THE COATINGS}

Microstructures of coatings are displayed in Fig. 7. All coatings contain typical lamellar microstructure. BST 100 and BST 150 samples have similar porosity, $5.4 \pm 0.6 \%$ and $4.9 \pm 0.6 \%$ respectively.

Sample sprayed at longest spray distance exhibits slightly higher porosity with higher standard deviation as well. Value of $8.6 \pm 1.8 \%$ shows that spray distance is most likely too long and resulting in less compacted coating. Please note, that typical spray distance for plasma spraying using F4 plasma torch is rarely longer than $150 \mathrm{~mm}$. When the coating's electrical properties and porosity values were compared, it is realizable that porosity is not the main factor affecting coatings behavior in the electrical field.

Vickers hardness data show decrease in hardness with increasing of spray distance. Observed values are 555, 477 and $325 \mathrm{HV}_{0.3}$ for BST 100 , BST 150 and BST 200 respectively. Standard deviation for all measurements was below $\pm 15 \mathrm{HV}_{0.3}$. Hardness of a thermal spray deposited material is governed not only by the intrinsic elastic properties of constituents forming the structure, but also by the interlamellar bonding between the splats and pore density. In plasma sprayed ceramics, the coating elastic properties are significantly lower compared to bulk counterparts. There is a clear correlation between particle diagnostic results on one side and hardness of the coatings on the other. Considering porosity, its low values are obtained for the shortest spray distance. 


\section{CONCLUSIONS}

In this article, an attempt was made to investigate the effect of amorphous phase content on electrical properties of atmospheric plasma sprayed $(\mathrm{Ba}, \mathrm{Sr}) \mathrm{TiO}_{3}$ coatings. Three set of samples were plasma spray deposited using different spray distances. Final coatings contained 5, 15 and $38 \mathrm{wt} . \%$ of amorphous phase. Results of DC resistivity measurements show clear correlation between amorphous phase content and electrical resistivity. Sample BST 150 containing 38 wt.\% of amorphous phase exhibits four orders of magnitude higher resistivity when compared to the BST 100 with 5 wt.\% of amorphous phase. Not only degree of crystallinity but also oxygen vacancies, preferably generated at short spray distances due to reduction in plasma atmosphere, affected the conductivity of the deposits. Loss factor value is linked to the resistivity of the material because a conduction mechanism of electrical losses is associated with electrical resistivity. BST 100 exhibits the highest relative permittivity for low frequencies as well as the highest loss factor for the whole frequency range. Other two samples containing significantly higher amorphous phase content have loss factor nearly ten times lower and much less dependent on frequency. Frequency dependence of relative permittivity for BST 150 and BST 200 is linear and the absolute value decreases with increase of amorphous phase content.

In general, increase in amorphous phase content results in an increase in DC resistivity and reduction in relative permittivity value for low frequencies. Frequency dependence of relative permittivity is weak for samples containing 15 wt.\% of amorphous phase content and more. Sample BST 200, with 15 wt.\% of amorphous phase content, exhibits the best electrical properties of all studied samples due to relatively high permittivity value and low frequency dependence on relative permittivity (200 for $1 \mathrm{kHz}$ ) and relatively low loss factor (0.05) in the whole frequency range. In contrary, its porosity is the highest and microhardness is the lowest. The porosity is therefore not the main parameter affecting coatings electrical properties. Based on literature research this level of mechanical properties is satisfactory. 


\section{ACKNOWLEDGEMENTS}

Authors thank to Dr. Zdenek Pala for XRD analysis. This work was supported by the Czech Science Foundation under Grant No. 14-36566G Multidisciplinary research center for advanced materials. Jiri Kotlan thanks to the Grant Agency of the Czech Technical University in Prague, grant No. SGS16/225/OHK3/3T/13 for electrical measurements financial support. Samples manufacturing was supported by the National Science Foundation Partnership for Innovation program under award IIP1114205.

\section{REFERENCES}

[1] N. Setter, R. Waser, Electroceramic materials, Acta Mater. 48 (2000)151-178.

[2] S. Sampath, Thermal Spray Applications in Electronics and Sensors: Past, Present, and Future, J. Therm. Spr. Tech. 19 (5) (2010) 921-949.

[3] Ce-Wen Nan, M. I. Bichurin, Shuxiang Dong, D. Viehland and G. Srinivasan, Multiferroic magnetoelectric composites: Historical perspective, status, and future directions, J. Appl. Phys. 103, $031101(2008)$

[4] M. M. Vijatović, J. D. Bobić, B. D. Stojanović, History and Challenges of Barium Titanate: Part II, Science of Sintering, 40 (2008) 235-244

[5] Z. Song, H. Liu, H. Hao, S. Zhang, M. Cao, Z. Yao, Z. Wang, W. Hu, Y. Shi, B. Hu, The Effect of Grain Boundary on the Energy Storage Properties of (Ba0.4Sr0.6)TiO3 Paraelectric Ceramics by Varying Grain Sizes, IEEE Transactions on Ultrasonics, Ferroelectrics, and Frequency Control, 62 (4) (2015) 609616. 
[6] A.H. Dent, A. Patel, J. Gutleber, E. Tormey, S. Sampath, H. Herman, High velocity oxy-fuel and plasma deposition of $\mathrm{BaTiO}_{3}$ and (Ba.Sr)TiO 3 , Mat. Sci. and Eng. B87 (2001) 23-30.

[7] K. Ahn, B.W Wessels, S. Sampath, Dielectric properties of plasma-spray-deposited BaTiO3 and Ba0.68Sr0.32TiO3 thick films, J. Mater. Res., 18 (5) (2003) 1227-31.

[8] K. Ahn, B.W. Wessels, R. Greenlaw, and S. Sampath, Dielectric Properties of Spray Deposited BaTiO3 and Ba0.68Sr0.32TiO3, Materials Research Society Proceedings: Electroactive Polymers and Rapid Prototyping, Direct Write Electronics, 2001.

[9] Z. Xing, H. Wang, L. Zhu, X. Zhou, Y. Huang, Properties of the BaTiO3 coating prepared by supersonic plasma spraying, J. Alloys Compd. 582 (2014) 246-252.

[10] P. Ctibor, H. Ageorges, V. Štengl, N. Murafa, I. Píš, T. Zahoranová, V. Nehasil, Z. Pala, Structure and properties of plasma sprayed $\mathrm{BaTiO} 3$ coatings: spray parameters versus structure and photocatalytic activity, Ceram. Int. 37 (2011) 2561-2567.

[11] A.H. Pakseresht, M.R. Rahimipour, M.R. Vaezi, M. Salehi, Effect of splat morphology on the microstructure and dielectricproperties of plasma sprayed barium titanate films, Appl. Surf. Sci. 324 (2015) 797-806.

[12] S. Sampath, H. Herman, Rapid solidification and microstructure development during plasma spray deposition, Journal of Thermal Spray Technology 5 (4) (1996) 445-456.

[13] P. Ctibor, J. Sedlacek, Z. Pala, Structure and properties of plasma sprayed BaTiO3 coatings after thermal posttreatment, Ceram. Int. 41 (6) (2015) 7453-7460.

[14] J. Kotlan, R.C. Seshadri, S. Sampath, P. Ctibor, Z. Pala, R. Musalek, On the dielectric strengths of atmospheric plasma sprayed A12O3, Y2O3, $\mathrm{ZrO} 2-7 \%$ Y2O3 and (Ba,Sr)TiO3 coatings, Ceram. Int. 41 (9) (2015) 11169-11176. 
[15] M.K. Reddy, S.V. Manorama, A.R. Reddy, Bandgap studies on anatase titanium dioxide. Materials Chemistry and Physics 2002;78:239-245.

[16] G. Mauer, R. Vaßen, D. Stöver, Comparison and Applications of DPV-2000 and Accuraspray-g3 Diagnostic Systems, J. Therm. Spr. Tech. 16 (2007) 414-424.

[17] A. Kalabukhov, R. Gunnarsson, J. Börjesson, E. Olsson, T. Claeson, D. Winkler, Effect of oxygen vacancies in the $\mathrm{SrTiO} 3$ substrate on the electrical properties of the LaAlO3/SrTiO3 interface, Phys. Rev. B 75 (2007) 121404(R)

[18] H.B. Xiong, L.L. Zheng, L. Li, A. Vaidya, Melting and oxidation behavior of in-flight particles in plasma spray process, Int. J. of Heat and Mass Trans. 48 (2005) 5121-5133.

[19] H.K. Seok, E.Y. Choi, P.R. Cha, M.C. Son, B.L. Choi, et al. Characterization of plasma-sprayed $\mathrm{Y}_{2} \mathrm{O}_{3}$ coating and investigation of its visual aspect change, Surf Coat Tech 205 (2011) 3341-3346.

[20] M.K. Reddy, S.V. Manorama, A.R. Reddy, Bandgap studies on anatase titanium dioxide, Mater. Chem. Phys. 78 (2002) 239-245.

[21] A. Kalabukhov, R. Gunnarsson, J. Börjesson, E. Olsson, T. Claeson, D. Winkler. Effect of oxygen vacancies in the $\mathrm{SrTiO} 3$ substrate on the electrical properties of the LaAlO3 SrTiO3 interface, Physb Rev. B. 75 (12) (2007) 121404. 


\section{FIGURE CAPTIONS}

Fig. 1. XRD patterns of BST FS and as-sprayed surfaces of three coatings.

Fig. 2. The time evolution of DC resistance measurement for the BST 150 sample.

Fig. 3. Volume resistivity results.

Fig. 4. Frequency dependence of relative permittivity.

Fig. 5. Frequency dependence of loss factor.

Fig. 6. The band gap estimation.

Fig. 7. SEM observations on polished cross sections of deposits. 


\section{TABLES}

Table 1: APS spray parameters employed for this study

\begin{tabular}{|l|l|}
\hline Parameter & Value / Unit \\
\hline Torch/ Nozzle diameter & $60 \mathrm{~kW}$ F4-MB-XL/ $8 \mathrm{~mm}$ \\
\hline Injector type/ diameter and angle & Single external/ $1.8 \mathrm{~mm} / 90^{\circ}$ \\
\hline Argon/ Hydrogen/ Carrier gas flow rates & $50 / 6 / 7$ lpm \\
\hline Powder make/ Size/ Feed rate & $\begin{array}{l}(\mathrm{Ba}, \mathrm{Sr}) \mathrm{TiO}_{3} \text { powder (Trans Tech Inc., USA)/ 5-45 } \mu \mathrm{m} / 30 \\
\text { gpm }\end{array}$ \\
\hline Spray Distance & 100,150 and $200 \mathrm{~mm}$ \\
\hline Current/ Voltage & $550 \mathrm{~A} / 64 \mathrm{~V}$ \\
\hline Raster speed/ Step (over-lap) size & $1000 \mathrm{mmps} / 3 \mathrm{~mm}$ \\
\hline
\end{tabular}

Table 2: In-flight surface temperature and velocities of the BST particles at different distances.

\begin{tabular}{|c|c|c|}
\hline Spray distance $(\mathrm{mm})$ & Surface Temperature $\left({ }^{\circ} \mathrm{C}\right)$ & Velocity $(\mathrm{m} / \mathrm{s})$ \\
\hline 100 & 2530 & 177 \\
\hline 150 & 2440 & 167 \\
\hline 200 & 2330 & 128 \\
\hline
\end{tabular}

Table 3: Rietveld analysis results of feedstock and coating deposits

\begin{tabular}{|c|c|c|c|}
\hline Sample ID & Lattice parameters $(\AA)$ & CDD $(\mathrm{nm})$ & Amorphous content (wt.\%) \\
\hline Feed Stock & $3.9632 \pm 0.0001$ & $55 \pm 1$ & - \\
\hline BST 100 & $3.9719 \pm 0.0002$ & $47 \pm 1$ & 5 \\
\hline BST 150 & $3.9721 \pm 0.0003$ & $55 \pm 2$ & 38 \\
\hline BST 200 & $3.9716 \pm 0.0001$ & $70 \pm 1$ & 15 \\
\hline
\end{tabular}


Figure 1

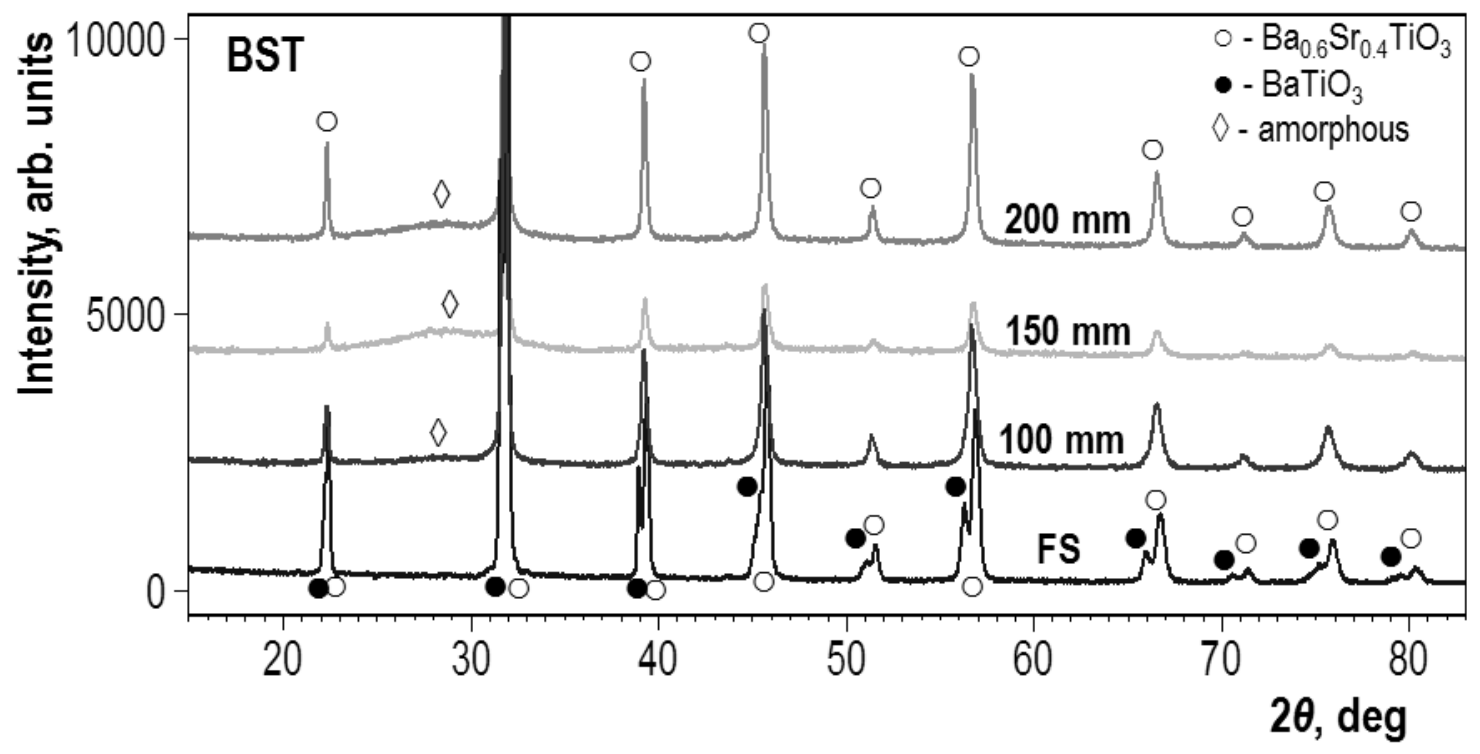


Figure 2

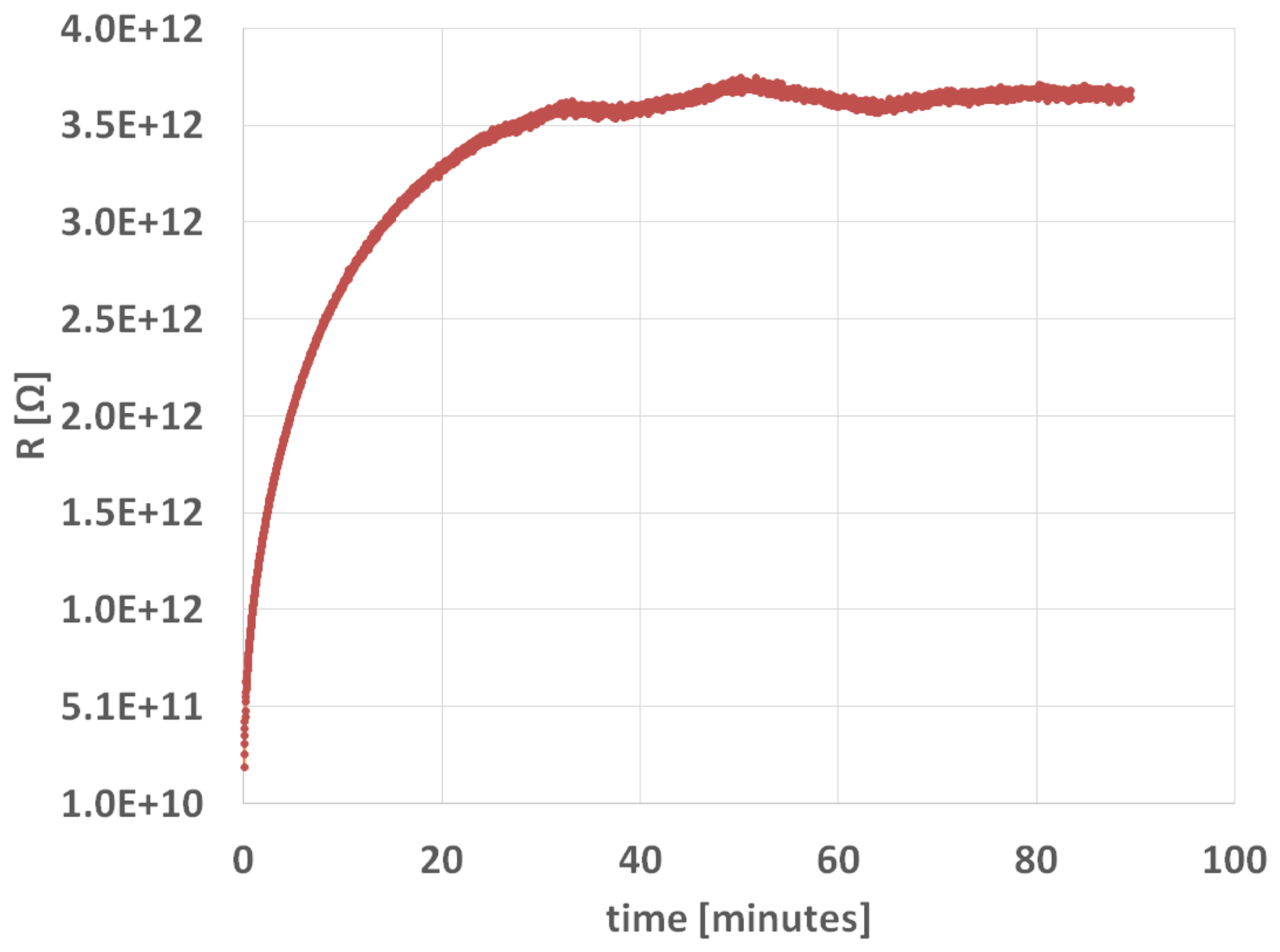




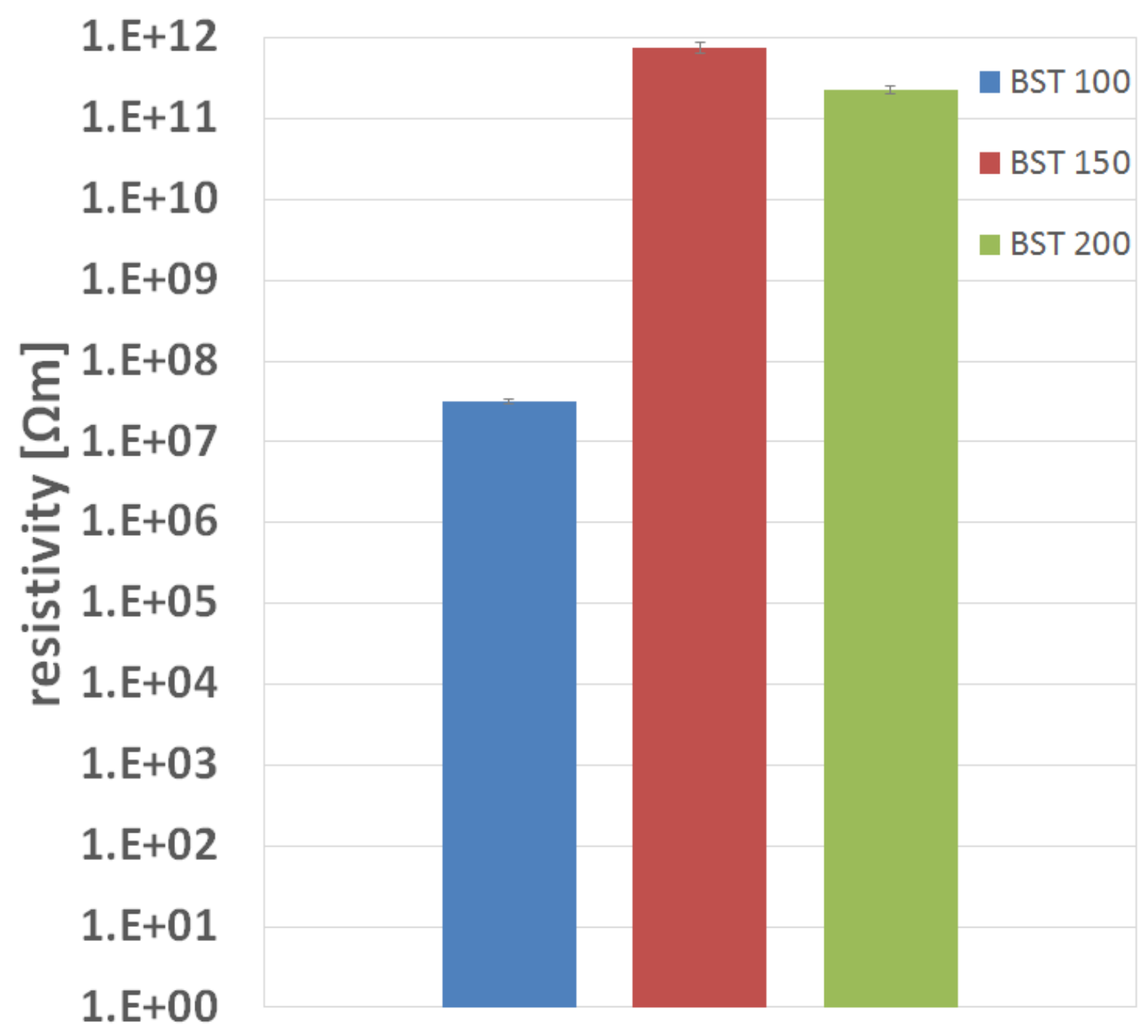


Figure 4

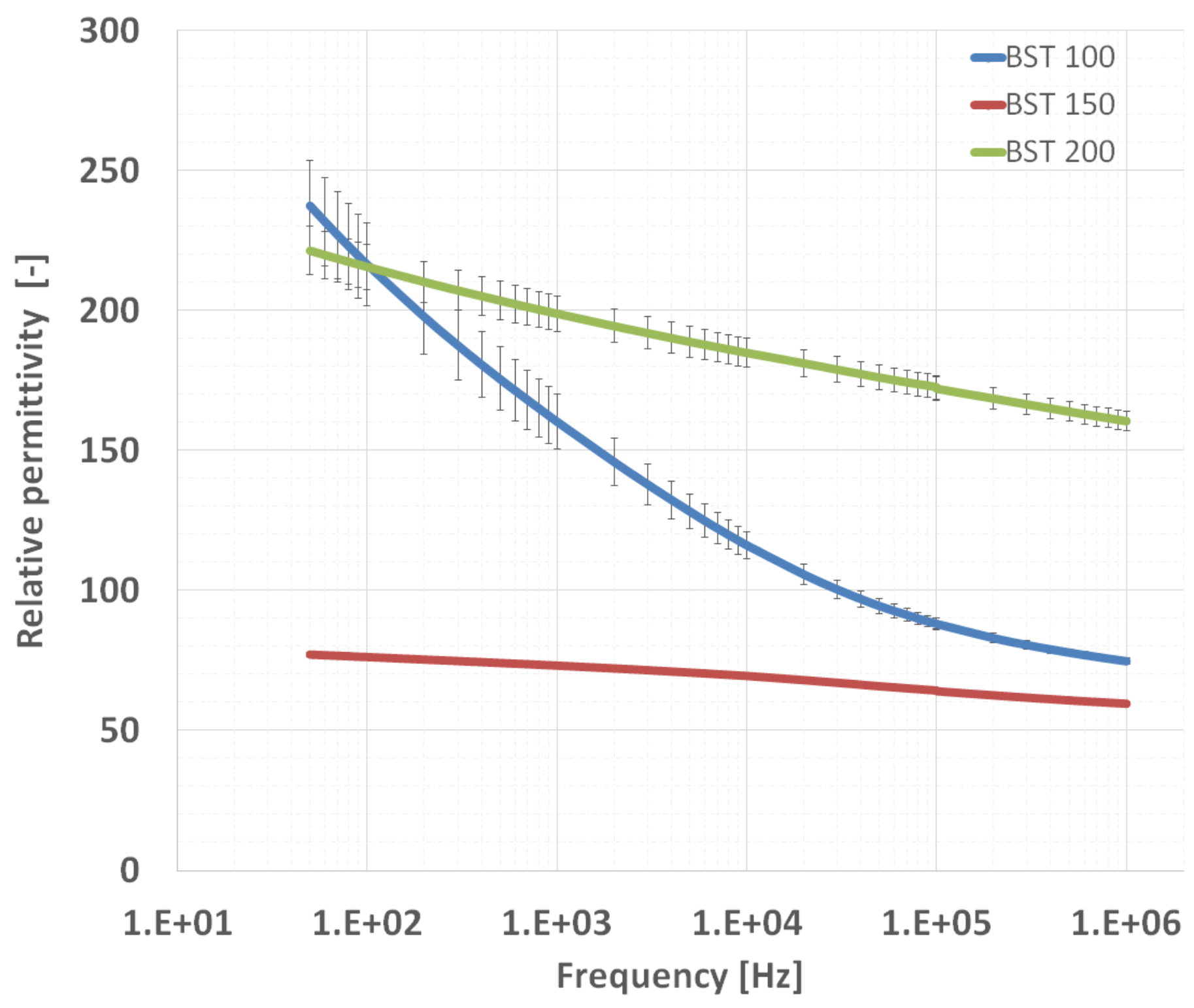


Figure 5

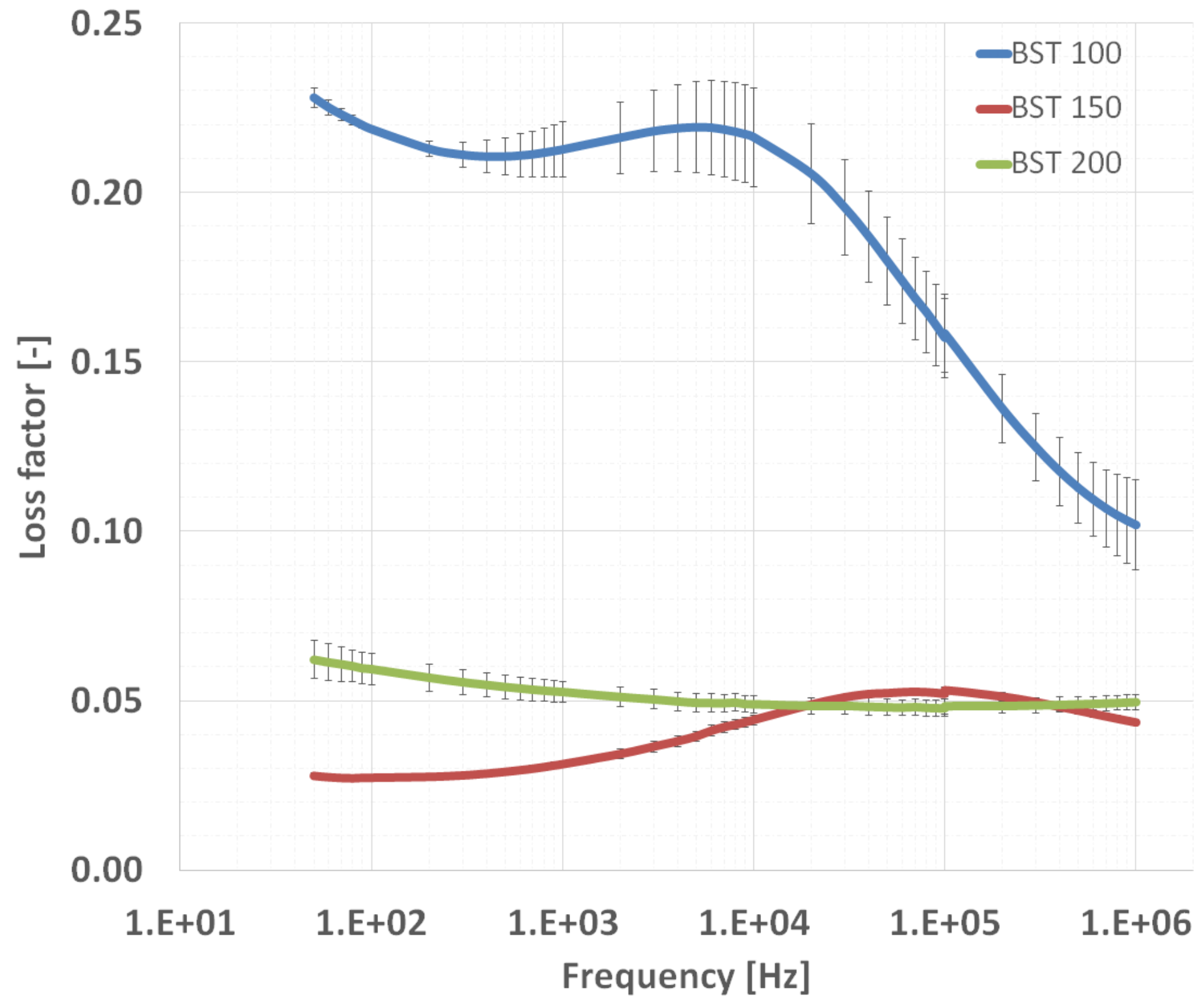




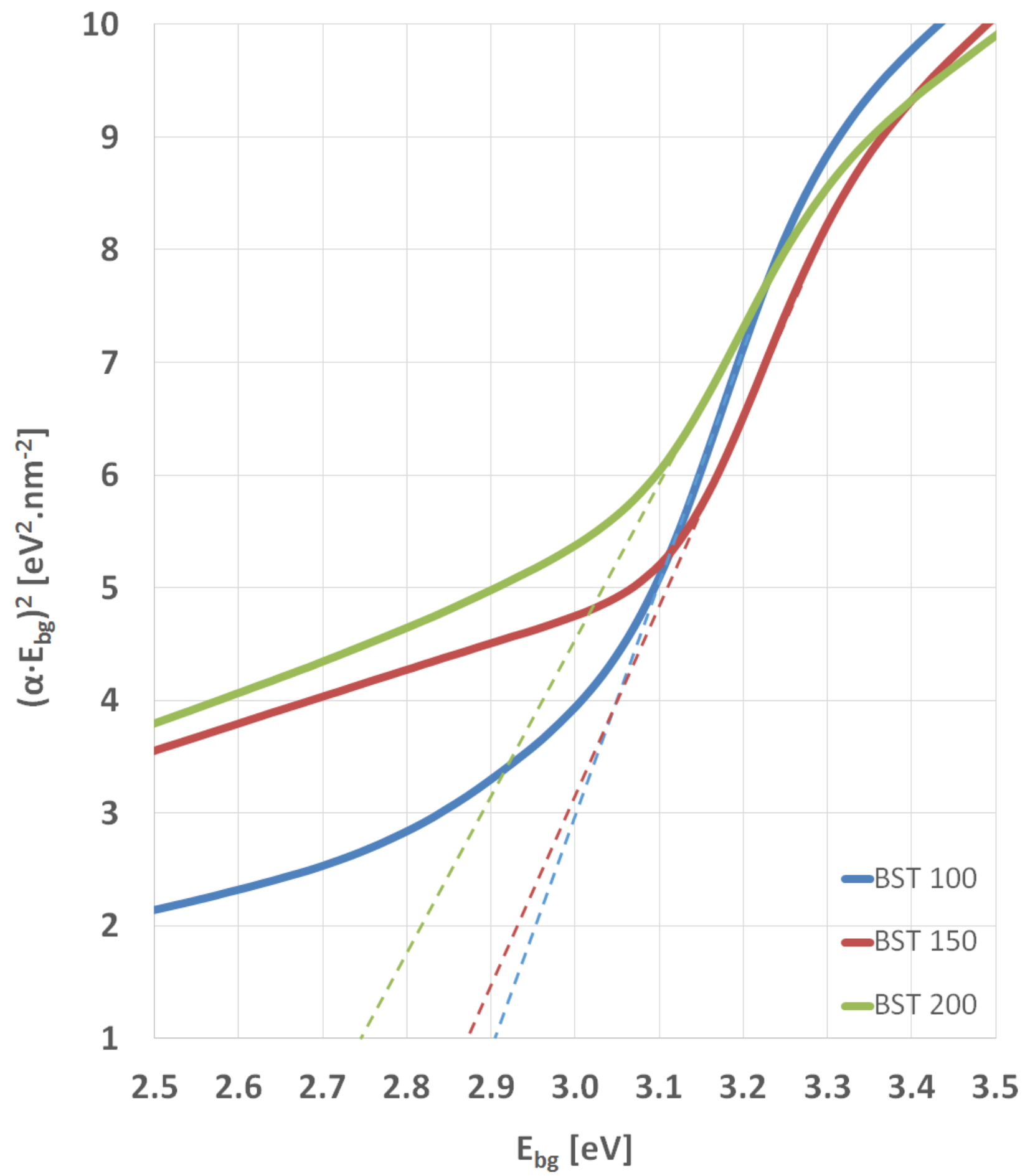


Figure 7

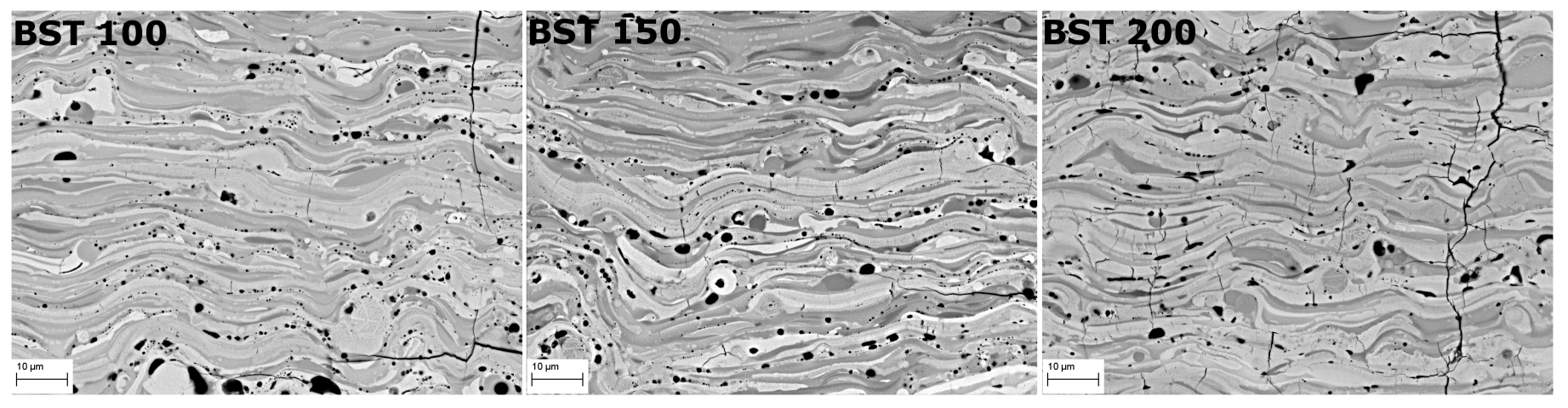

